\title{
GMR
}

\section{MiR-200c inhibits metastasis of breast tumor via the downregulation of Foxf2}

\author{
T. Zhang, J.G. Wan, J.B. Liu and M. Deng \\ Department of General Surgery, \\ The First Affiliated Hospital of Henan University of Science and Technology, \\ Henan, China \\ Corresponding author: M. Deng \\ E-mail: miaodengd@sina.com
}

Genet. Mol. Res. 16 (3): gmr16038971

Received July 14, 2016

Accepted December 9, 2016

Published August 17, 2017

DOI http://dx.doi.org/10.4238/gmr16038971

Copyright (C) 2017 The Authors. This is an open-access article distributed under the terms of the Creative Commons Attribution ShareAlike (CC BY-SA) 4.0 License.

\begin{abstract}
The forkhead box F2 (Foxf2) gene suppresses epithelial-mesenchymal transition via the modulation of transcription of zinc finger E-box-binding homeobox 1 (Zeb1) and epithelial (E)-cadherin, thereby inhibiting tumor metastasis. Additionally, the specific binding of microRNA (miR)-200c to Foxf2 mRNA impedes metastatic pulmonary cancer. However, the role of miR-200c in breast cancer is still unknown. Therefore, in this study, miR-200c mimics were transfected into the highly metastatic breast cancer cell line MDA-MB-231. Their invasion and migration abilities were observed by scratch and transwell migration assays. Real-time PCR was used to detect mRNA levels of Foxf2, Zeb1, and E-cadherin, whereas Foxf2 protein level was determined by western blot analysis. Our results showed that, compared to the control group, miR-200c inhibited the migration or invasion of MDA-MB-231 cells. Real-time PCR and western blot analysis exhibited significant decreases in Foxf2 expression in the presence of miR-200c, along with a decrease in Zeb1 and increase in E-cadherin mRNA expressions. Thus, our preliminary data demonstrated that miR-200c could inhibit the metastasis of breast
\end{abstract}


cancer cells by downregulating Foxf2 expression, providing leads for the discovery of a novel breast cancer treatment.

Key words: Breast cancer cell; Epithelial-mesenchymal transition; miRNA-200c; Foxf2; E-cadherin; Zeb1

\section{INTRODUCTION}

Breast cancer is the third most popular malignant tumor worldwide and is the most common cancer in women, affecting about $12 \%$ women worldwide, with rapidly increasing incidence and mortality rates (Berrada et al., 2010. It has been estimated that in 2015, around 268,600 new cancer cases and 72,000 cancer-related deaths occurred in China and 2.8 million women were affected by breast cancer (McGuire et al., 2015). According to the subtyping guidelines by St. Gallen International Breast Cancer Congress (Goldhirsch et al., 2011), basal-like type (triple-negative breast cancer type mainly) is more invasive due to the lack of estrogen receptor, progesterone receptor, and human epidermal growth factor receptor 2 expressions and overexpression of basal-like molecular markers in breast cancer cells, making them insensitive to either molecular targeting or endocrine treatment (Goldhirsch et al., 2011). Recent studies have shown that epithelial-mesenchymal transition (EMT) plays a critical role in the invasion-metastasis cascade (Kumar et al., 2016). EMT represses cell-cell adhesion through inhibition of epithelial (E)-cadherin, zonula occludens-1, occludin, claudin-1, and claudin-7, and facilitates multiple immunosuppression, drug resistance, and evasion of apoptosis, thus promoting cancer progression and metastasis (Chaffer and Weinberg, 2011). Studies have revealed that a multitude of factors, such as forkhead box M1 (FoxM1)caveolin-1, tumor growth factor $\beta$, nuclear factor-kappa B, Notch-1, and hypoxia trigger EMT, resulting in metastasis (Ellenrieder et al., 2011; Huang et al., 2012; Shimojo et al., 2013). Interestingly, Foxf2 can stimulate EMT, further accelerating tumor metastasis (Kundu et al., 2016). Foxf2 gene belongs to the forkhead/winged helix transcription factor family, and its product can specifically recognize and bind the binding regions on DNA sequences in its monomeric form; thus, it recruits co-activating molecules to initiate transcription, playing a crucial role during embryonic development and tissue differentiation (Nik et al., 2013). During such processes, the relationship between Foxf2 and EMT is the key to illustrating the tumor metastasis mechanism. Some studies have indicated that EMT is significantly impeded byFoxf2 deficiency, and that Foxf2 exerts an inhibitory effect on EMT by regulating the transcription of TWIST1 in basal-like breast cancer cells (Marschall and Beuers, 2013; van den Brink and Rubin, 2013; Wang et al., 2015). Another study on gene expression profiling demonstrated that FOXF2 was highly co-expressed with basal- and metastasis-related genes in breast cancer, but was frequently silenced in luminal-type and human epidermal growth factor receptor 2-positive breast cancers, indicating that it plays dual roles depending on the breast tumor subtype (Lo et al., 2016).

MicroRNAs (miRNAs) are a group of highly conserved RNA molecules of 22-24 nt length and are important in the endogenous regulatory pathway for protein expression (Bartel, 2009; Tekirdag et al., 2013; Zhang et al., 2016). Animal miRNAs are usually partially complementary to the 3 '-untranslated region of the target gene, leading to the less efficient translation of the mRNA into proteins (Bartel, 2009). A previous study on metastatic pulmonary cancer has shown that miR-200c specifically binds the Foxf2 mRNA to inhibit the translation

Genetics and Molecular Research 16 (3): gmr16038971 
of Foxf2, which binds zinc finger E-box-binding homeobox 1 (Zeb1) (Ahmad et al., 2011). This elevates E-cadherin expression and retards EMT, arresting cell migration. Moreover, the miR-200 family of miRNAs is downregulated in basal-like breast cancer cell line MDAMB-231, with a more significant change in their expression levels than other family members (Castilla et al., 2012). However, the correlation between miR-200c and Foxf2 in breast cancer cells is still unknown. Thus, the purpose of this study was to show that miR-200c has a similar function in breast cancer cells as it does in pulmonary cancer, which may provide profound evidence for the development of novel breast cancer treatments.

\section{MATERIAL AND METHODS}

\section{Cell line and reagents}

Human breast cancer cell line MDA-MB-231 was purchased from American Type Culture Collection (ATCC, USA). MiR-200c mimics were designed and synthesized by Gimma (Gimma, China). Gibco Dulbecco's modified Eagle's medium (DMEM) was purchased from Life Technologies (Thermofisher Scientific, USA). Fetal bovine serum was obtained from Gibco (Thermofisher Scientific). Lipofectamine 3000 and mRNA primers were purchased from Invitrogen (Thermofisher Scientific). RNA extraction kit was used for RNA extraction (TaKaRa, Japan), ReverTra Ace kit for reverse transcription, and rTaq DNA Polymerase for PCR were obtained from Toyobo (Japan). Transwell chamber (6.5 mm transwell, with $8.0 \mathrm{~mm}$ pore size polycarbonate membrane insert) was a product of Corning (USA). Foxf2 polyclonal antibody was purchased from Abcam (USA).

\section{Cell culture}

Transient transfection of miRNA with Lipofectamine 3000 was performed based on manufacturer instructions. One day before transfection, cells were seeded on a 6-well plate $\left(2 \times 10^{5}\right.$ cells per well) in antibiotic-free high-glucose DMEM medium. Cells were divided into control (no treatment), miR-NC (blank transfection), and miR-200c transfection groups. After the cells reached $60-70 \%$ confluence, $3.75 \mu \mathrm{L}$ Lipofectamine 3000 was diluted in $125 \mu \mathrm{L}$ DMEM, whereas equal volume of DMEM was used to dilute $30 \mathrm{nmol} \mathrm{miR-200c}$ mimics or miR-NC. These two solutions were mixed and incubated for $5 \mathrm{~min}$ at $25^{\circ} \mathrm{C}$ to form the transfection mixture, which was then added to culture plates $(1.5 \mathrm{~mL}$ each well). After incubating it for $36-48 \mathrm{~h}$, further experiments were performed.

\section{Scratch assay}

Forty-eight hours after transfection, a scratch was made in the center of the 6-well plate using pipette tips. D-hanks' solution was used to wash the cells and culture medium was added. Experiments were carried out in triplicates. Images were captured at 0 and $24 \mathrm{~h}$, to assess the wound closure rate.

\section{Transwell cell migration assay}

Forty-eight hours after transfection, $1.1 \mathrm{~mL}$ high-glucose DMEM medium was added 
to a 24-well plate and a transwell chamber. Cells were counted and adjusted to a concentration of $10^{5}$ per $\mathrm{mL}$. Serum-free cell suspension $(0.2 \mathrm{~mL})$ containing $0.4 \%$ bovine serum albumin was then added to the chamber, and $1.1 \mathrm{~mL}$ high-glucose DMEM medium was added to the lower chamber. The transwell was incubated for $24 \mathrm{~h}$ and was fixed in methanol. After staining with $5 \mathrm{~g} / \mathrm{L}$ hematoxylin, images were taken to count cell numbers in six randomly selected fields, with a microscope (magnification 200X; Olympus CX41, Japan). Experiments were carried out in triplicates.

\section{Total RNA extraction, reverse transcription, and real-time PCR}

After $48 \mathrm{~h}$ of transfection, total RNA was extracted from cells using RNA extraction kit (TaKaRa), following manufacturer protocol. After determining RNA concentration, in vitro reverse transcription was performed the kit (Promega, USA) containing $4 \mu \mathrm{L} 25$ $\mathrm{mM} \mathrm{MgCl}, 2 \mu \mathrm{L} 10 \mathrm{X}$ reverse transcription buffer, $2 \mu \mathrm{L} 10 \mathrm{mM}$ dNTP mixture, $0.5 \mu \mathrm{L}$ ribonuclease inhibitor, $15 \mathrm{U}$ AMV reverse transcriptase, $0.5 \mathrm{mg}$ random primers, $1 \mathrm{mg}$ total RNA, and nuclease-free water to a final volume of $20 \mu \mathrm{L}$, at $42^{\circ} \mathrm{C}$ for $15 \mathrm{~min}$ and $85^{\circ} \mathrm{C}$ for denaturation Real-time PCR was then performed using SYBR Premix Ex Taq GC kit (TaKaRa) with $7.5 \mu \mathrm{L}$ SYBR Premix, $10 \mathrm{mM}$ forward and reverse primers, and distilled water to a final volume of $15 \mu \mathrm{L}$. The following PCR conditions were used: denaturation at $94^{\circ} \mathrm{C}$ for $30 \mathrm{~s}$, followed by 40 cycles of denaturation at $94^{\circ} \mathrm{C}$ for $5 \mathrm{~s}$ and annealing at $60^{\circ} \mathrm{C}$ for $30 \mathrm{~s}$, with LightCycler 480 system (Roche Diagnostics, USA). Primer sequences and amplicon lengths are listed in Table 1. Glyceraldehyde 3-phosphate (GAPDH) was selected as internal reference. Relative gene expression was semi-quantitatively analyzed by the $2^{-\Delta \Delta \mathrm{Ct}}$ method, where $2^{-\Delta \Delta \mathrm{Ct}}=$ gene copy number in the test group/gene copy number in the control. Experiments were carried out in triplicates.

\begin{tabular}{|c|c|c|}
\hline Gene & Primer position & $\begin{array}{l}\text { Primer sequence }\left(5^{\prime}-3^{\prime}\right) \\
\end{array}$ \\
\hline \multirow{2}{*}{ Foxf2 } & Upstream & 5'-TGCACTCCAGCATGTCCTCCTA-3' \\
\hline & Downstream & 5'-CGCTAGCTGAGGGATGGAAAG-3' \\
\hline \multirow[t]{2}{*}{$Z e b l$} & Upstream & 5'-GCACAACCAAGTGCAGAAGA-3' \\
\hline & Downstream & 5'-CATTTGCAGATTGAGGCTGA-3' \\
\hline \multirow[t]{2}{*}{ E-cadherin $(\mathrm{CDHI})$} & Upstream & 5'-CGGACGATGATGTGAACACC-3' \\
\hline & Downstream & 5'-TTGCTGTTGTGCTTAACCCC-3' \\
\hline \multirow[t]{2}{*}{ GAPDH } & Upstream & 5'-AGAAGGCTGGGGCTCATTTG-3' \\
\hline & Downstream & 5'-AGGGGCCATACACAGTCTTC-3' \\
\hline
\end{tabular}

\section{Western blot analysis}

After transfection, $10^{6}$ cells were lysed in RIPA buffer (Thermo Fisher Scientific, USA) and were centrifuged at 12,000 $g$ for $5 \mathrm{~min}$. Supernatants were extracted to purify total proteins, which were quantified using the bicinchoninic acid assay. Protein samples were diluted to equal amounts and were separated by SDS-PAGE at $120 \mathrm{~V}$ for $2 \mathrm{~h}$. The separated proteins were then transferred to a polyvinylidene membrane (Bio-rad, USA) at $15 \mathrm{~V}$ for 30 min and were blocked with $10 \%$ defatted milk powder at $37^{\circ} \mathrm{C}$ for $2 \mathrm{~h}$. Rabbit anti-human Foxf2 polyclonal antibody $(1: 1000)$ or GAPDH $(1: 1000)$ at $20 \mu \mathrm{L}$ final volume was incubated at $4{ }^{\circ} \mathrm{C}$ overnight. After this, the membrane was rinsed three times (10 min each) with Tris-buffered 
saline-Tween- 20 at $25^{\circ} \mathrm{C}$. Goat anti-rabbit secondary antibody, at $20 \mu \mathrm{L}$ final volume, was then added for 1-hour incubation, followed by the enhanced chemiluminiscence chromogenic substrate. Quantity One software (Bio-rad, USA) was employed to analyze the blotting bands, in which the ratio of intensity of target protein to that of GAPDH bands was calculated to reflect the relative protein level.

\section{Statistical analysis}

SPSS 17.0 software (IBM, USA) was used to process the data collected, which are reported as means $\pm \mathrm{SD}$. All data were analyzed by ANOVA. A statistical significance was defined at $\mathrm{P}<0.05$.

\section{RESULTS}

\section{MiR-200c inhibited the migration of breast cancer cells MDA-MB-231}

To evaluate the effect of miR-200c on the invasion and metastasis capacity of tumor cells, we implemented a scratch assay to test the cell movement. Typically, we found that cells showed a budding-pattern growth from the edge of the scratch to the center, in 0 to $24 \mathrm{~h}$. Compared to the control and miR-NC groups, the migration of cells significantly decreased after transfection with miR-200c mimics (Figure 1A). The result also showed that the wounds closed $(\sim 75 \%)$ on miR-220c overexpression. In contrast, control or miR-NC cells showed $\sim 55 \%$ wound closure (Figure 1B).

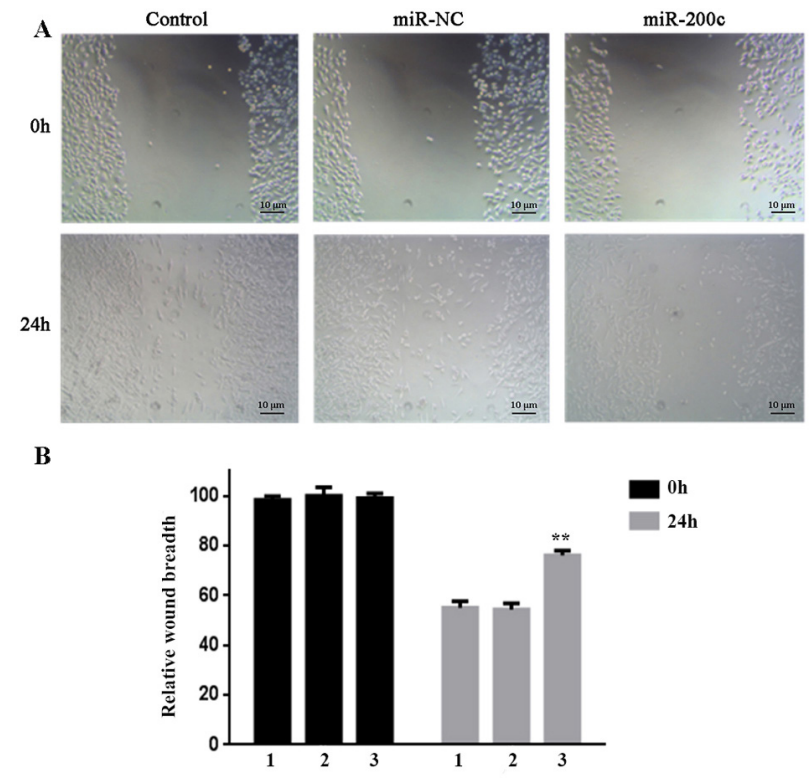

Figure 1. Analysis of breast cancer cell migration by scratch assay. A. Cell migration after 0 and $24 \mathrm{~h}$ (magnification 200X). B. Quantitative analysis of cell migration assayed in A. 1, Control group; 2, miR-NC group; and 3, miR$200 \mathrm{c}$ group. Data are reported as mean $\pm \mathrm{SD}$ for $\mathrm{N}=3$. $* * \mathrm{P}<0.01$, compared to the control group. 
Similarly, further in vitro invasion assay with transwell plate revealed a statistically small amount of migrated cells $(\sim 50 \%)$ in the miR-200c group, compared to those in the control or miR-NC group ( $100 \%)$, suggesting that cell migration was inhibited after miR200c transfection (Figure 2).

A

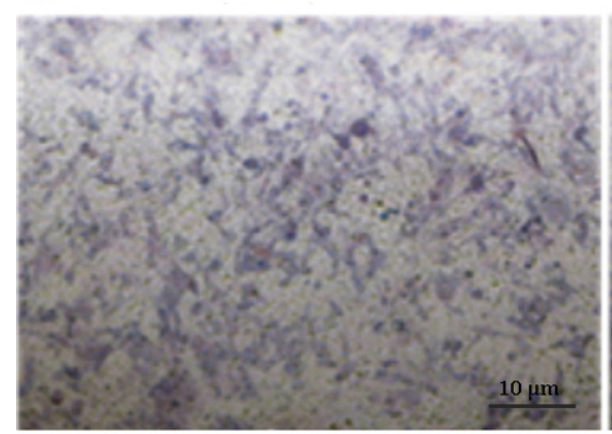

$\mathrm{C}$

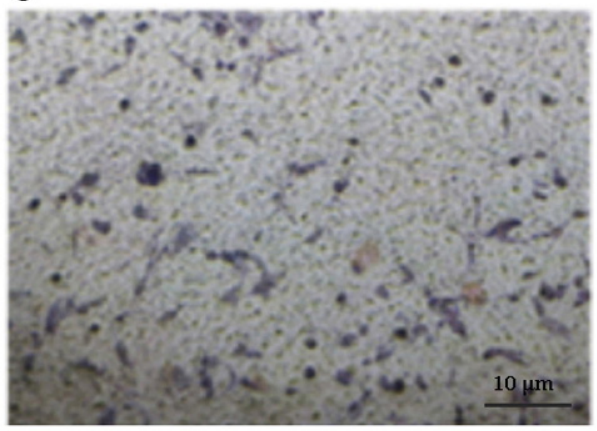

$\mathrm{B}$

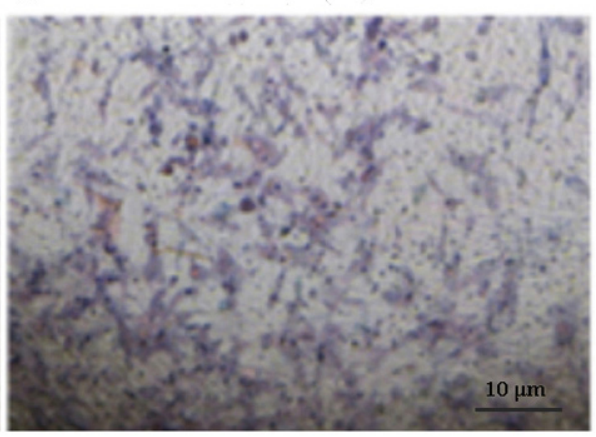

$\mathrm{D}$

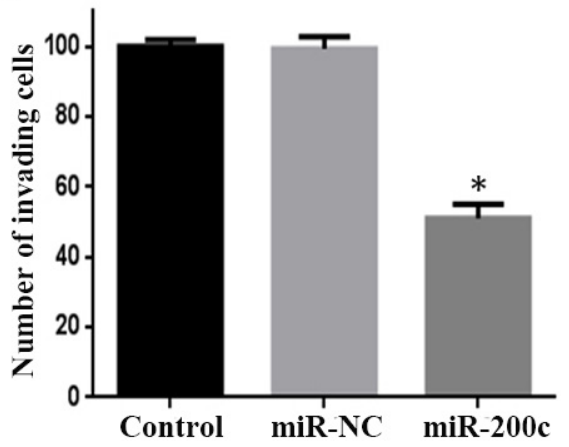

Figure 2. Analysis of MDA-MB-231 cell migration by transwell assay. Cell migration in control group (A), miRNC group (B), and miR-200c group (C) (magnification 400X). D. Quantitative analysis of cell migration assayed in $\mathrm{A}, \mathrm{B}$, and $\mathrm{C}$. Data are reported as means $\pm \mathrm{SD}$ for $\mathrm{N}=3$. ${ }^{*} \mathrm{P}<0.01$, compared to the control group.

\section{MiR-200c altered the mRNA levels of Foxf2, Zeb1, and E-cadherin}

We detected the mRNA expressions of Foxf2, Zeb1, and E-cadherin, which play significant roles in tumor metastasis. Our real-time PCR data showed that mRNA levels of Fox2 and Zeb1 were significantly decreased, but mRNA level of E-cadherin in cells transfected with miR-200c was upregulated, compared to that in the control group (Figure 3). These results indicated that the overexpression of miR-200c suppressed the expression of Foxf2 and Zeb1, whereas it induced E-cadherin expression.

\section{MiR-200c downregulated the expression of Foxf2 protein}

To further assess the effect of miR-200c at protein level, we detected the expression of Foxf2 protein via western blotting. The result demonstrated that the protein level of Foxf2 statistically decreased to about $50 \%$ of its basal level in the miR-200c group, compared to 
that in the control or miR-NC group, being consistent with the data on mRNA level $(\mathrm{P}<0.05$; Figure 4).
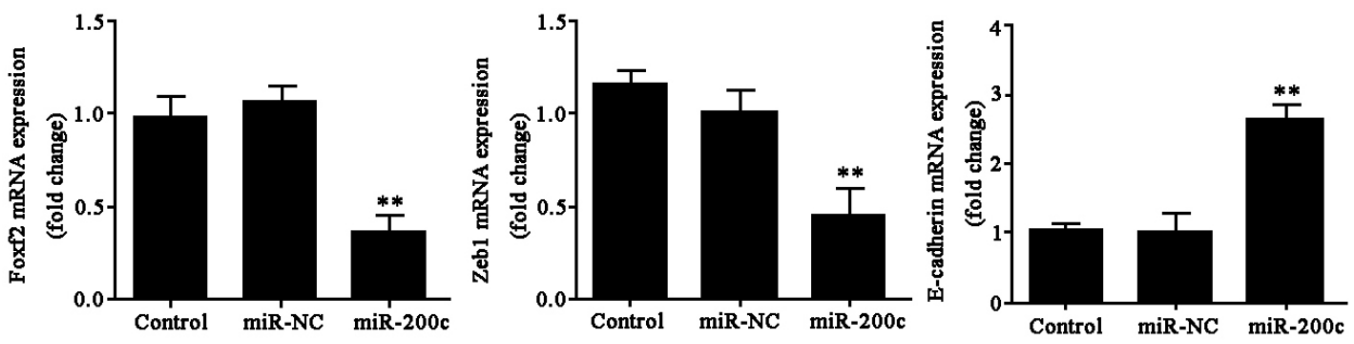

Figure 3. Effect of miR-200c on mRNA levels of Foxf2, Zeb1, and E-cadherin. $* * \mathrm{P}<0.01$, compared to the control group. Foxf2, forkhead box f2; Zeb1, zinc finger E-box-binding homeobox 1; E-cadherin, epithelial cadherin.
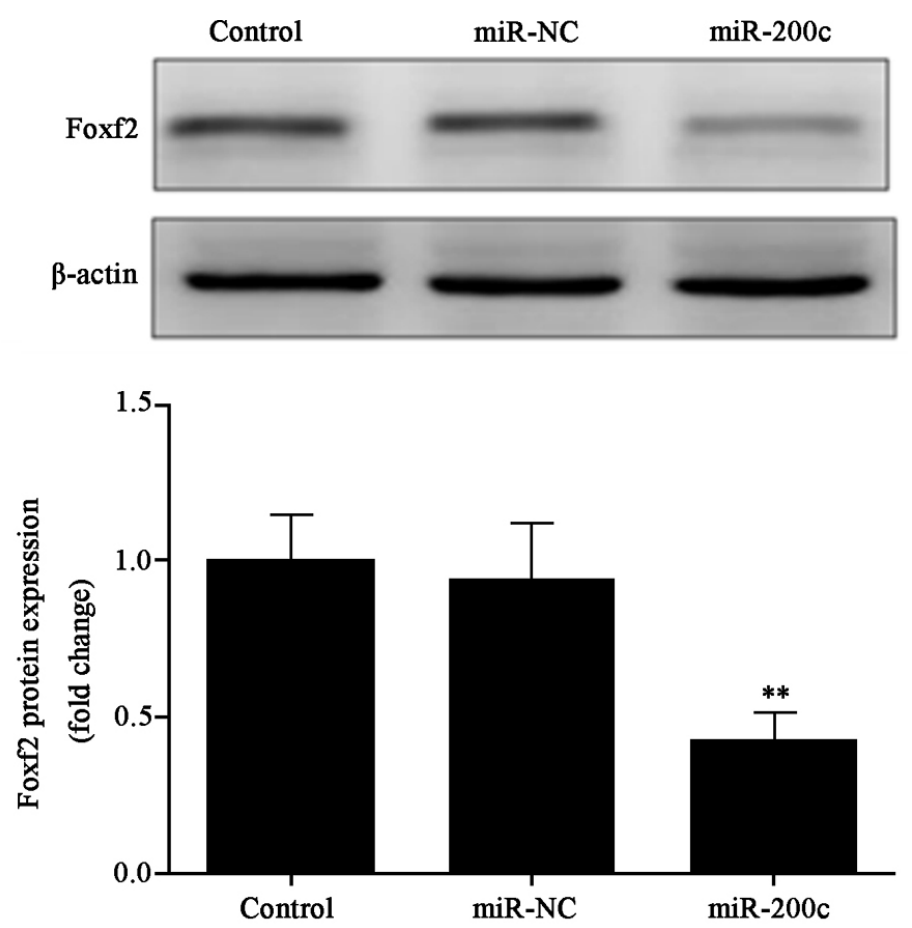

Figure 4. Foxf2 protein expression level after miR-200c transfection. $\beta$-actin was used as a loading control. $* * \mathrm{P}<0.01$, compared to the control group. Foxf2, forkhead box $\mathrm{f} 2$.

\section{DISCUSSION}

The occurrence of breast cancer is regulated by various genetic, hormonal, and environmental factors, including age, height, alcohol consumption, use of estrogenprogesterone contraceptives, X-ray or gamma radiation, tobacco smoking, and shiftwork 
involving circadian disruption (Parkin et al., 2011). Generally, metastasis and invasion of tumor in the host involves multiple steps. For example, integrin, paracrine Wnt- $\beta$-catenin signaling plays a significant role in regulating breast cancer progression, and growth factor receptors, apoptosis markers, and signaling cascades change to various degrees, among which EMT is an important marker of the early stages of metastatic tumor (Allen et al., 2014). EMT is crucial for the establishment of multicellular organisms, including newly formed mesenchymal cells, which can exhibit locomotory and invasive phenotypes, suggesting that EMT contributes to the progression of carcinoma (Vincent-Salomon and Thiery, 2003). EMT was originally used to describe certain morphological changes occurring in epithelial cells during embryonic development (Ye et al., 2015). In the process of tumor invasion, metastasis, and progression, the de-differentiation and alteration of polymorphism is a typical feature (Wei et al., 2015). A fibroblast-like morphology in the later stages of the disease was progressively observed during EMT in squamous cell carcinoma of the skin (Oft et al., 2002). Data have revealed that EMT prolongs the survival time of cancer cells during movement from their primary site to distal metastasis site (Iwatsuki et al., 2010). During EMT, many tumor cells from the primary tumor lesion lose their epithelial polarity and cell-to-cell adhesion via the suppression of E-cadherin, zonula occludens-1, occludin, claudin- 1 , and claudin- 7 , thus acquiring the ability to invade and migrate (McCart Reed et al., 2016). In addition, recent studies suggest that a multitude of factors are involved in the regulation of EMT. Foxf2, which belongs to the forkhead transcription factor family, can stimulate EMT (Kundu et al., 2016). E-cadherin, a calciumdependent transmembrane glycoprotein, was thought to be involved in oral carcinogenesis via Wnt pathway dysregulation and as an EMT marker (Chaw et al., 2012). Zeb1, which encodes a zinc finger and homeodomain transcription factor, is positively correlated to EMT (DíazLópez et al., 2015).

As endogenous non-coding small RNAs, miRNAs can modulate the expression of target proteins via degrading mRNA or inhibiting translation (Elgheznawy et al., 2015). Recent studies have revealed the important role of miR-200 family in maintaining the epithelial status. Alteration in miR-200 family transcription leads to change in expression of EMT-targeted modulatory factors Zeb1, Snail, and transcription-specific factor Sp1 (Díaz-López et al., 2015). Zeb family initiates protein expression via a negative feedback mechanism (Hilmarsdóttir et al., 2015. A study by Hur et al. (2013) revealed that one of the miR-200 family members, miR-200c, downregulates the expression of Zeb family and vimentin proteins and induces the expression of E-cadherin in human colorectal cancer metastasis. Similarly, our data on breast cancer demonstrated that the expression of Zeb1 decreased, whereas that of E-cadherin increased, in the miR-200c group. Additionally, we found that both the mRNA and protein levels of Foxf2 in MDA-MB-231 breast cancer cells were downregulated by miR-200c, which was consistent with a recent study on pulmonary cancer suggesting that Foxf2 was under the direct regulation of miR-200 (Kundu et al., 2016).

FOX proteins are a family of transcription factors that play critical roles in regulating cell growth, proliferation, differentiation, and longevity (Tuteja and Kaestner, 2007). Research shows the vital involvement of FOX family in cancer onset and progression, and miRNAs play a crucial regulatory role in tumors via the modulation of these FOX proteins (Zhang et al., 2015; Wang et al., 2016). Foxf2 gene belongs to the forkhead/winged helix transcription factor family and has been implicated as an oncogene that modulates metastasis of various tumors (Nilsson et al., 2010). Our preliminary data exhibited that migration of breast cancer cell MDA-MB-231 was repressed by miR-200c, and the expression of Foxf2 was downregulated

Genetics and Molecular Research 16 (3): gmr16038971 
correspondingly. Coincidentally, recent studies have shown that other members of the Fox family, such as FoxM1 and FoxC1, can induce EMT, thus, activating tumor invasion and metastasis (Sarrió et al., 2008. Therefore, the overexpression of miR-200c impedes tumor progression via the inhibition of Fox-EMT cascade. Other studies have also indicated the role of Foxf2 in inducing EMT and tumor migration in pulmonary carcinoma, possibly by binding to Zeb1 and inhibiting E-cadherin expression at transcription level (Kundu et al., 2016). Our study also validated that in breast cancer cells MDA-MB-231, the transfection of miR-200c significantly reduced Zeb1, whereas it elevated E-cadherin expression. This indicated that the inhibition of Foxf2 expression by miR-200c, to eliminate its binding to Zeb1 and prevent degradation of E-cadherin, leads to the repression of EMT and retardation of tumor invasion. However, our study had some limitations. As another study contends that in human breast cancer samples, the loss of E-cadherin is not commonly observed in EMT and is not necessary (Hollestelle et al., 2013), the precise anti-tumor mechanism of miR-200c, in regulating the cascades involving Foxf2, Zeb1, and E-cadherin-EMT, requires to be further investigated.

In summary, this study further illustrated the critical role of miR-200 family in regulating EMT of breast cancer cells and revealed that miR-200c might affect Zeb1/E-cadherin expression to further eliminate EMT and inhibit tumor metastasis. This offers leads for the discovery of a precise effective target for molecular targeting therapy against breast cancer.

\section{Conflicts of interest}

The authors declare no conflict of interest.

\section{ACKNOWLEDGMENTS}

We thank the anonymous reviewers for reviewing this manuscript.

\section{REFERENCES}

Ahmad A, Aboukameel A, Kong D, Wang Z, et al. (2011). Phosphoglucose isomerase/autocrine motility factor mediates epithelial-mesenchymal transition regulated by miR-200 in breast cancer cells. Cancer Res. 71: 3400-3409. http:// dx.doi.org/10.1158/0008-5472.CAN-10-0965

Allen MD, Thomas GJ, Clark S, Dawoud MM, et al. (2014). Altered microenvironment promotes progression of preinvasive breast cancer: myoepithelial expression of av $\beta 6$ integrin in DCIS identifies high-risk patients and predicts recurrence. Clin. Cancer Res. 20: 344-357. http://dx.doi.org/10.1158/1078-0432.CCR-13-1504

Bartel DP (2009). MicroRNAs: target recognition and regulatory functions. Cell 136: 215-233. http://dx.doi.org/10.1016/j. cell.2009.01.002

Berrada N, Delaloge S and André F (2010). Treatment of triple-negative metastatic breast cancer: toward individualized targeted treatments or chemosensitization? Ann. Oncol. 21 (Suppl 7): vii30-vii35. http://dx.doi.org/10.1093/annonc/ $\underline{\operatorname{mdq} 279}$

Castilla MÁ, Díaz-Martín J, Sarrió D, Romero-Pérez L, et al. (2012). MicroRNA-200 family modulation in distinct breast cancer phenotypes. PLoS One 7: e47709. http://dx.doi.org/10.1371/journal.pone.0047709

Chaffer CL and Weinberg RA (2011). A perspective on cancer cell metastasis. Science 331: 1559-1564. http://dx.doi. org/10.1126/science. 1203543

Chaw SY, Majeed AA, Dalley AJ, Chan A, et al. (2012). Epithelial to mesenchymal transition (EMT) biomarkers--Ecadherin, beta-catenin, APC and Vimentin--in oral squamous cell carcinogenesis and transformation. Oral Oncol. 48: 997-1006. http://dx.doi.org/10.1016/j.oraloncology.2012.05.011

Díaz-López A, Díaz-Martín J, Moreno-Bueno G, Cuevas EP, et al. (2015). Zeb1 and Snail1 engage miR-200f transcriptional and epigenetic regulation during EMT. Int. J. Cancer 136: E62-E73. http://dx.doi.org/10.1002/ijc.29177

Genetics and Molecular Research 16 (3): gmr16038971 
Elgheznawy A, Shi L, Hu J, Wittig I, et al. (2015). Dicer cleavage by calpain determines platelet microRNA levels and function in diabetes. Circ. Res. 117: 157-165. http://dx.doi.org/10.1161/CIRCRESAHA.117.305784

Ellenrieder V, Hendler SF, Boeck W, Seufferlein T, et al. (2001). Transforming growth factor beta1 treatment leads to an epithelial-mesenchymal transdifferentiation of pancreatic cancer cells requiring extracellular signal-regulated kinase 2 activation. Cancer Res. 61: 4222-4228.

Goldhirsch A, Wood WC, Coates AS, Gelber RD, et al.; Panel members (2011). Strategies for subtypes--dealing with the diversity of breast cancer: highlights of the St. Gallen International Expert Consensus on the Primary Therapy of Early Breast Cancer 2011. Ann. Oncol. 22: 1736-1747. http://dx.doi.org/10.1093/annonc/mdr304

Hilmarsdóttir B, Briem E, Sigurdsson V, Franzdóttir SR, et al. (2015). MicroRNA-200c-141 and $\Delta$ Np63 are required for breast epithelial differentiation and branching morphogenesis. Dev. Biol. 403: 150-161. http://dx.doi.org/10.1016/j. ydbio.2015.05.007

Hollestelle A, Peeters JK, Smid M, Timmermans M, et al. (2013). Loss of E-cadherin is not a necessity for epithelial to mesenchymal transition in human breast cancer. Breast Cancer Res. Treat. 138: 47-57. http://dx.doi.org/10.1007/ $\underline{\text { s10549-013-2415-3 }}$

Huang C, Qiu Z, Wang L, Peng Z, et al. (2012). A novel FoxM1-caveolin signaling pathway promotes pancreatic cancer invasion and metastasis. Cancer Res. 72: 655-665. http://dx.doi.org/10.1158/0008-5472.CAN-11-3102

Hur K, Toiyama Y, Takahashi M, Balaguer F, et al. (2013). MicroRNA-200c modulates epithelial-to-mesenchymal transition (EMT) in human colorectal cancer metastasis. Gut 62: 1315-1326. http://dx.doi.org/10.1136/gutjnl-2011-301846

Iwatsuki M, Mimori K, Yokobori T, Ishi H, et al. (2010). Epithelial-mesenchymal transition in cancer development and its clinical significance. Cancer Sci. 101: 293-299. http://dx.doi.org/10.1111/j.1349-7006.2009.01419.x

Kumar K, Chow CR, Ebine K, Arslan AD, et al. (2016). Differential regulation of ZEB1 and EMT by MAPKinteracting protein kinases (MNK) and eIF4E in pancreatic cancer. Mol. Cancer Res. 14: 216-227. http://dx.doi. org/10.1158/1541-7786.MCR-15-0285

Kundu ST, Byers LA, Peng DH, Roybal JD, et al. (2016). The miR-200 family and the miR-183 96 182 cluster target Foxf2 to inhibit invasion and metastasis in lung cancers. Oncogene 35: 173-186. http://dx.doi.org/10.1038/ onc. 2015.71

Lo PK, Lee JS, Liang X and Sukumar S (2016). The dual role of FOXF2 in regulation of DNA replication and the epithelialmesenchymal transition in breast cancer progression. Cell. Signal. 28: 1502-1519. http://dx.doi.org/10.1016/j. cellsig.2016.06.021

Marschall HU and Beuers U (2013). When bile acids don’t get amidated. Gastroenterology 144: 870-873. http://dx.doi. org/10.1053/j.gastro.2013.03.018

McCart Reed AE, Kutasovic JR, Vargas AC, Jayanthan J, et al. (2016). An epithelial to mesenchymal transition programme does not usually drive the phenotype of invasive lobular carcinomas. J. Pathol. 238: 489-494. http:// dx.doi.org/10.1002/path.4668

McGuire A, Brown JA, Malone C, McLaughlin R, et al. (2015). Effects of age on the detection and management of breast cancer. Cancers (Basel) 7: 908-929. http://dx.doi.org/10.3390/cancers7020815

Nik AM, Reyahi A, Pontén F and Carlsson P (2013). Foxf2 in intestinal fibroblasts reduces numbers of Lgr5(+) stem cells and adenoma formation by inhibiting Wnt signaling. Gastroenterology 144: 1001-1011. http://dx.doi.org/10.1053/j. gastro.2013.01.045

Nilsson J, Helou K, Kovács A, Bendahl PO, et al. (2010). Nuclear Janus-activated kinase 2/nuclear factor 1-C2 suppresses tumorigenesis and epithelial-to-mesenchymal transition by repressing Forkhead box F1. Cancer Res. 70: 2020-2029. http://dx.doi.org/10.1158/0008-5472.CAN-09-1677

Oft M, Akhurst RJ and Balmain A (2002). Metastasis is driven by sequential elevation of H-ras and Smad2 levels. Nat. Cell Biol. 4: 487-494. http://dx.doi.org/10.1038/ncb807

Parkin DM, Boyd L and Walker LC (2011). 16. The fraction of cancer attributable to lifestyle and environmental factors in the UK in 2010. Br. J. Cancer 105 (Suppl 2): S77-S81. http://dx.doi.org/10.1038/bjc.2011.489

Sarrió D, Rodriguez-Pinilla SM, Hardisson D, Cano A, et al. (2008). Epithelial-mesenchymal transition in breast cancer relates to the basal-like phenotype. Cancer Res. 68: 989-997. http://dx.doi.org/10.1158/0008-5472.CAN-07-2017

Shimojo Y, Akimoto M, Hisanaga T, Tanaka T, et al. (2013). Attenuation of reactive oxygen species by antioxidants suppresses hypoxia-induced epithelial-mesenchymal transition and metastasis of pancreatic cancer cells. Clin. Exp. Metastasis 30: 143-154. http://dx.doi.org/10.1007/s10585-012-9519-8

Tekirdag KA, Korkmaz G, Ozturk DG, Agami R, et al. (2013). MIR181A regulates starvation- and rapamycin-induced autophagy through targeting of ATG5. Autophagy 9: 374-385. http://dx.doi.org/10.4161/auto.23117

Tuteja G and Kaestner KH (2007). SnapShot: forkhead transcription factors I. Cell 130: 1160. http://dx.doi.org/10.1016/j. $\underline{\text { cell.2007.09.005 }}$

Genetics and Molecular Research 16 (3): gmr16038971 
van den Brink GR and Rubin DC (2013). Foxf2: a mesenchymal regulator of intestinal adenoma development. Gastroenterology 144: 873-876. http://dx.doi.org/10.1053/j.gastro.2013.03.016

Vincent-Salomon A and Thiery JP (2003). Host microenvironment in breast cancer development: epithelial-mesenchymal transition in breast cancer development. Breast Cancer Res. 5: 101-106. http://dx.doi.org/10.1186/bcr578

Wang DS, Zhang HQ, Zhang B, Yuan ZB, et al. (2016). miR-133 inhibits pituitary tumor cell migration and invasion via down-regulating FOXC1 expression. Genet. Mol. Res. 15. http://dx.doi.org/10.4238/gmr.15017453

Wang QS, Kong PZ, Li XQ, Yang F, et al. (2015). FOXF2 deficiency promotes epithelial-mesenchymal transition and metastasis of basal-like breast cancer. Breast Cancer Res. 17: 30. http://dx.doi.org/10.1186/s13058-015-0531-1

Wei SC, Fattet L, Tsai JH, Guo Y, et al. (2015). Matrix stiffness drives epithelial-mesenchymal transition and tumour metastasis through a TWIST1-G3BP2 mechanotransduction pathway. Nat. Cell Biol. 17: 678-688. http://dx.doi. org $/ 10.1038 / \mathrm{ncb} 3157$

Ye X, Tam WL, Shibue T, Kaygusuz Y, et al. (2015). Distinct EMT programs control normal mammary stem cells and tumour-initiating cells. Nature 525: 256-260. http://dx.doi.org/10.1038/nature14897.

Zhang B, Gui LS, Zhao XL, Zhu LL, et al. (2015). FOXO1 is a tumor suppressor in cervical cancer. Genet. Mol. Res. 14: 6605-6616. http://dx.doi.org/10.4238/2015.June.18.3

Zhang YH, Wang QQ, Li H, Ye T, et al. (2016). MiR-124 radiosensitizes human esophageal cancer cell TE-1 by targeting CDK4. Genet.Mol.Res. 15: gmr.15027893. 